\title{
Determinação de coeficiente de Poisson do substrato rochoso a partir de análise dos dados sísmicos de onda P e onda PS registradas apenas no plano vertical
}

Isabella Tomasella Auad* (IPECI/UNISANTOS), Oleg Bokhonok (IAG-USP \& IPECI/UNISANTOS), Liliana Alcazar Diogo (IAGUSP), Victor Jorge de Oliveira Marum (IPECI/UNISANTOS)

Copyright 2016, SBGf - Sociedade Brasileira de Geofísica

Este texto foi preparado para a apresentação no VII Simpósio Brasileiro de Geofísica, Ouro Preto, 25 a 27 de outubro de 2016. Seu conteúdo foi revisado pelo Comitê Técnico do VII SimBGf, mas não necessariamente representa a opinião da SBGf ou de seus associados. É proibida a reprodução total ou parcial deste material para propósitos comerciais sem prévia autorização da SBGf.

\section{Resumo}

Esse trabalho apresenta uma ferramenta importante de investigação indireta de subsuperfície para uma melhor avaliação da geologia e das propriedades geotécnicas das áreas que serão usadas para construção de obras voltadas às necessidades de infraestrutura.

Os resultados apresentados mostram a possibilidade de determinar a razão $\mathrm{Vp} / \mathrm{Vs}$ e coeficiente de Poisson a partir dos tempos de trânsito das ondas PP e PSv registrados com receptor vertical. Os valores indicam que o substrato rochoso no local de estudo é constituído predominantemente pelos sedimentos argilosos saturados.

\section{Introdução}

Nos tempos atuais surge a necessidade cada vez maior de construção de obras voltadas às necessidades de infraestrutura, e a falta de espaço físico nas grandes metrópoles tem levado à ocupação dos espaços subterrâneos (como por exemplo para a instalação de túneis, reservatórios de retenção de cheias, dutos para cabos elétricos e de fibra ótica, etc.). Para a elaboração desses projetos e sua execução é necessário ter um bom conhecimento da geologia e das propriedades geotécnicas da área.

O coeficiente de Poisson ( $\sigma$ ) é um dos parâmetros mais requisitados para estudos geotécnicos e é definido como sendo a razão da tensão transversal pela tensão longitudinal sofrida por um corpo quando aplicada uma tensão unidirecional, compressiva ou distensiva, (Sheriff, 2002). Ou seja, o parâmetro que define o quanto o solo deforma no sentido horizontal em relação à deformação no sentido do carregamento. Também relaciona esta deformação às velocidades de onda compressional Vp e onda cisalhante Vs (Equação 1).

$$
\sigma=\frac{\left(\frac{1}{2}\right)\left(\frac{V p}{V s}\right)^{2}-1}{\left(\frac{V p}{V s}\right)^{2}-1}
$$

A importância da utilização das velocidades Vp e Vs está na caracterização das propriedades da rocha. A velocidade da onda $P$ embora seja útil, é uma função de três parâmetros independentes (módulo volumétrico, módulo de cisalhamento e densidade), tornando-a um indicador ambíguo de litologia. Calcula-se, então, a razão
Vp/Vs, que independe da densidade, para inferir informações mais precisas da litologia, baseadas nas propriedades geotécnicas do solo (Kearey et al., 2002).

A sísmica multicomponente, por sua vez, permite o registro tanto das ondas $P$ quanto das ondas $S$. No entanto, o valor alto do equipamento para aquisição dos dados sísmicos multicomponentes e a aparente complexidade de análise destes dados impedem uso amplo desta tecnologia.

Neste trabalho apresentamos uma metodologia para obter a razão $\mathrm{Vp} / \mathrm{Vs}$ e o coeficiente de Poisson $(\sigma)$ a partir do registro sísmico de reflexão registrado apenas em plano vertical, ou seja, a partir do registro sísmico convencional gerando e registrando energia sísmica no plano vertical.

\section{Local de Estudo}

Para esse estudo foram escolhidos os dados adquiridos dentro do campus da Universidade de São Paulo, situada na zona oeste do município de São Paulo, Brasil. A geologia neste local é representada por sedimentos terciários da Formação Itaquaquecetuba da Bacia Sedimentar de São Paulo que situa-se sobre o embasamento pré-cambriano. $\mathrm{Na}$ figura 1, está apresentada uma seção geológica elaborada através da correlação dos 3 poços existentes na área.

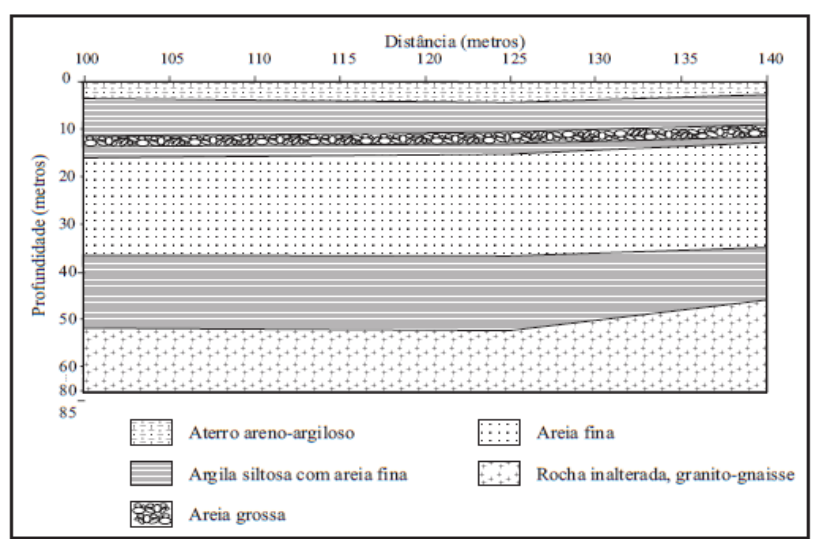

Figura 1 - Seção geológica obtida da correlação dos três poços existentes na área de estudo 2 (Adaptado de Borges, 2002).

\section{Metodologia}

A ideia central deste trabalho consiste em aproveitar a decomposição vetorial das ondas PP e PS no plano $z-x$. Nesta situação é possível registrar ambas as ondas com 
Determinação de coeficiente de Poisson do substrato rochoso a partir de análise dos dados sísmicos de onda P e onda PS2 registradas apenas no plano vertical

receptor vertical e usar essa informação para obter a razão Vp/Vs e o coeficiente de Poisson.

A Figura 3a é uma representação habitual do registro de ondas PP e PSv, que não leva em conta a decomposição das ondas $P$ e Sv no plano $z-x$, na direção vertical e horizontal radial (Figura 2). A representação que considera a decomposição do campo de onda multicomponente está na Figura 3b. Portanto para um meio isotrópico no plano z-x são registrados oito eventos refletidos para a mesma interface e não quatro.

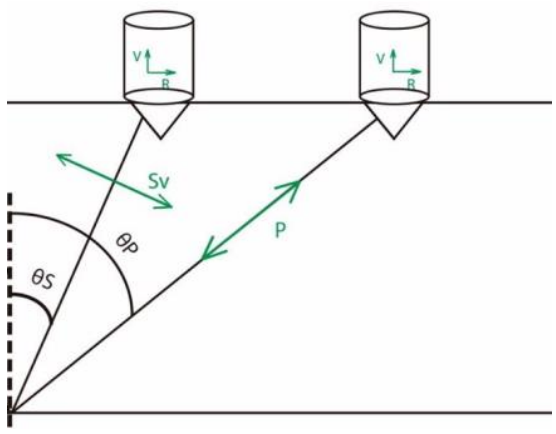

Figura 2 - llustração de decomposição das ondas P e Sv nas direções vertical $(z)$ e horizontal radial $(x)$.

\begin{tabular}{|c|c|c|}
\hline FONTE & RADIAL & VERTICAL \\
\hline RADIAL & SvSv & SvP \\
\hline VERTICAL & PSv & PP \\
\hline
\end{tabular}

(a)

\begin{tabular}{|c|c|c|}
\hline FONTE & RADIAL & VERTICAL \\
\hline \multirow{2}{*}{ RADIAL } & SvSv & SvSv \\
\hline & SvP & SvP \\
\hline \multirow{2}{*}{ VERTICAL } & PP & PP \\
\hline & PSv & PSv \\
\hline
\end{tabular}

(b)

Figura 3 - Representação das componentes registradas em um sistema de coordenadas cartesianas (XZ) assumindo meio isotrópico: (a) ondas PP, PSv, SvP e SvSv; (b) ondas PP, PSv, SvP e SvSv decompostas nas direções vertical $(z)$ e horizontal radial $(x)$.

\section{Aquisição dos dados}

Para adquirir os dados foi realizado um experimento chamado de Análise de Ruído (walkaway test), deslocando a fonte sísmica e deixando os receptores fixos (Figura 4).

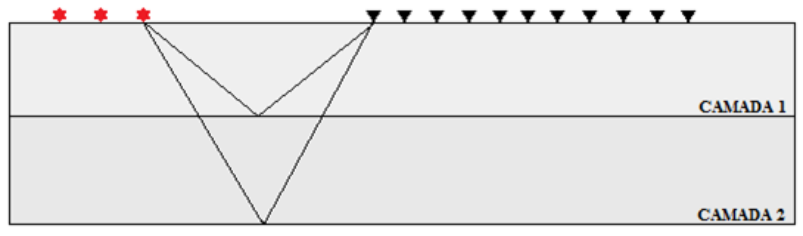

Figura 4 - Ilustração esquemática de geometria de teste de Análise de Ruído com receptores fixos.

$\mathrm{Na}$ tabela 1 estão apresentados os parâmetros de aquisição utilizados no local de estudo. Estes parâmetros foram escolhidos com base no conhecimento prévio da geologia do local.

\begin{tabular}{|l|l|}
\hline $\begin{array}{l}\text { Número de grupos de } \\
\text { receptores }\end{array}$ & 32 (fixos) \\
\hline Afastamento mínimo & $2 \mathrm{~m}$ \\
\hline Afastamento máximo & $128 \mathrm{~m}$ \\
\hline $\begin{array}{l}\text { Espaçamento entre os } \\
\text { grupos de receptores }\end{array}$ & $2 \mathrm{~m}$ \\
\hline Número de pontos de tiro & 2 \\
\hline Geofones & Horizontal de $28 \mathrm{~Hz}$ e Vertical de $40 \mathrm{~Hz}$ \\
\hline Fontes & Marreta de $6 \mathrm{~kg}$ impactada sobre: \\
\hline placa de metal acoplada no solo \\
\hline Acoplamento dos geofones & Ponteira de 0,1 \\
\hline Intervalo de amostragem & $0,25 \mathrm{~ms}$ \\
\hline Comprimento do registro & $700 \mathrm{~ms}$ \\
\hline Filtro corta-baixa analógico & $3 \mathrm{~Hz}$ \\
\hline
\end{tabular}

Tabela 1 - Parâmetros de aquisição dos dados sísmicos de reflexão na forma de Análise de Ruído.

$\mathrm{Na}$ figura 5 estão apresentados os registros sísmicos brutos adquiridos utilizando fonte vertical e receptores horizontais direcionados na direção radial (figura 5a) e receptores verticais (figura $5 b$ ).
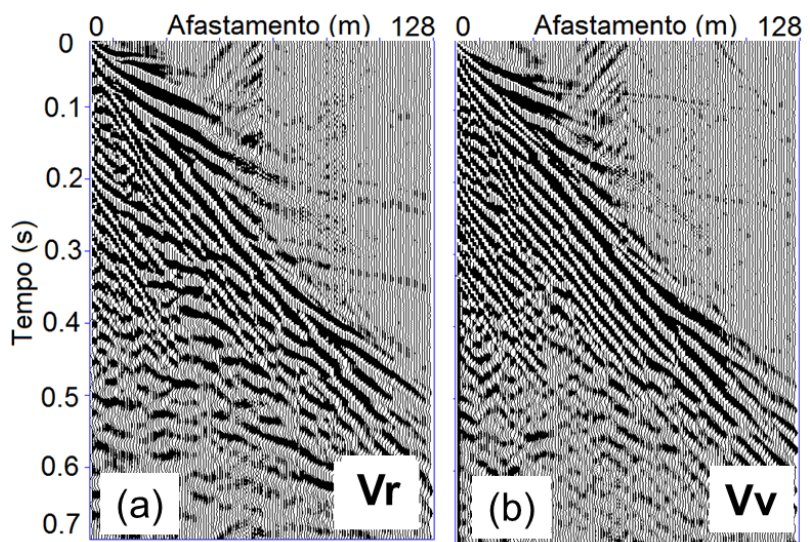

Figura 5 - Registro sísmico bruto adquirido na área de estudo: (a) Fonte Vertical - Receptor Horizontal Radial; (b) Fonte Vertical - Receptor Vertical. 


\section{Processamento dos dados}

As ondas $\mathrm{P}$ e PSv foram processadas de forma individual, isto devido à esses dois tipos de onda possuírem diferentes conteúdos de frequência e velocidades. Para o processamento dos dados foi usado o pacote gratuito Seismic Unix (CWP/SU) (Stockwell \& Cohen, 1998). Na Figura 6, os registros foram processados com o intuito de preservar a presença da energia da onda $P$.

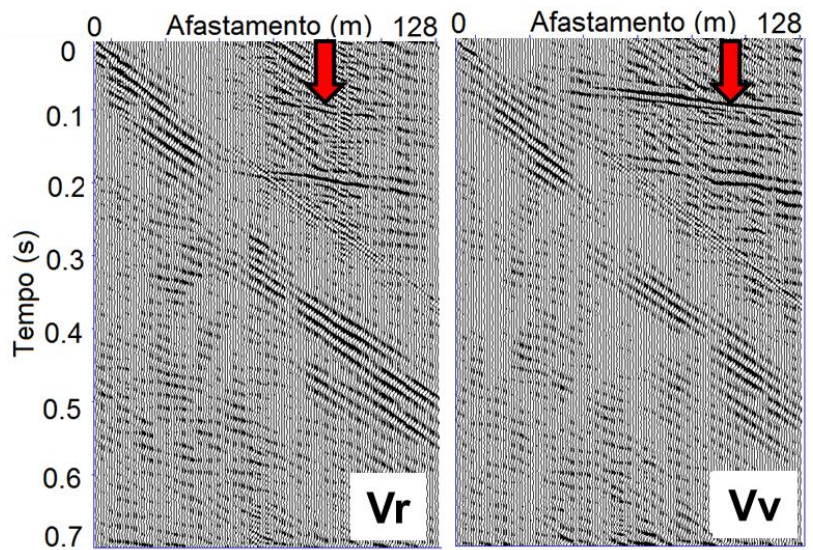

Figura 6 - Dado sísmico adquirido na área de estudo e processado com 0 intuito de preservar a presença de energia de onda $\mathrm{P}$. Os eventos de onda $\mathrm{P}$ estão indicados com setas vermelhas.

Na Figura 7, os registros foram processados com o intuito de preservar a presença da energia da onda PSv.

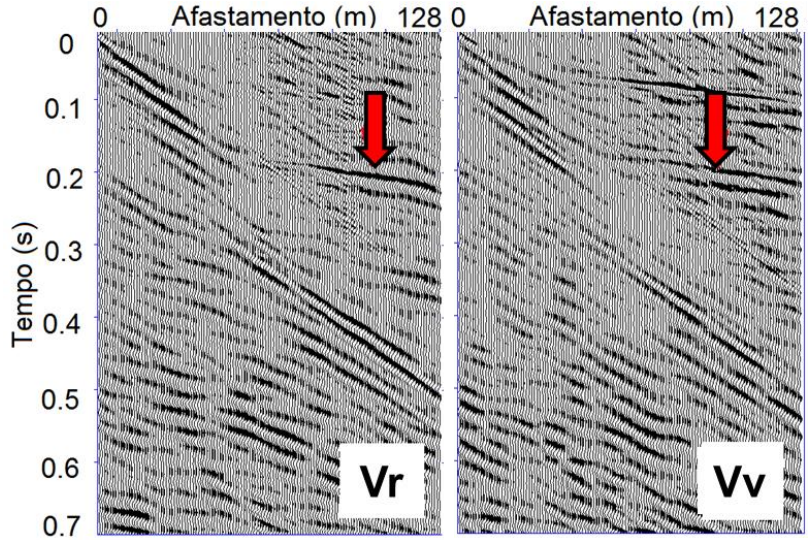

Figura 7 - Dado sísmico adquirido na área de estudo e processado com o intuito de preservar a presença de energia de onda PSv. Os eventos de onda PSv estão indicados com setas vermelhas.

Observando os dados sísmicos processados verificou-se que as ondas sísmicas PP e PSv foram registradas tanto com receptor vertical, como também com receptor horizontal radial. Entretanto, apenas o registro efetuado com receptor vertical já é suficiente para obter as informações de tempos de trânsito de onda PP e PSv.

\section{Interpretacão/Inversão de tempos de trânsito}

Após a leitura dos tempos observados dos eventos de onda PP e PSv registrados com receptor vertical (Figuras 6 e 7) foi efetuada a inversão dos tempos utilizando a equação da hipérbole deslocada (Malovichko, 1978).

A função objetivo utilizada no procedimento de inversão foi L2 que quantificou a semelhança entre os tempos de trânsito calculados e observados. Portanto, o melhor ajuste dos dados calculados aos observados está associado ao valor mínimo da função objetivo de tempos de trânsito da onda PP e onda PSv refletidos. Os parâmetros estimados são o tempo normal, velocidade de RMS e parâmetro S (coeficiente de heterogeneidade).

Os resultados obtidos estão apresentados na Figura 8 e Tabela 2.
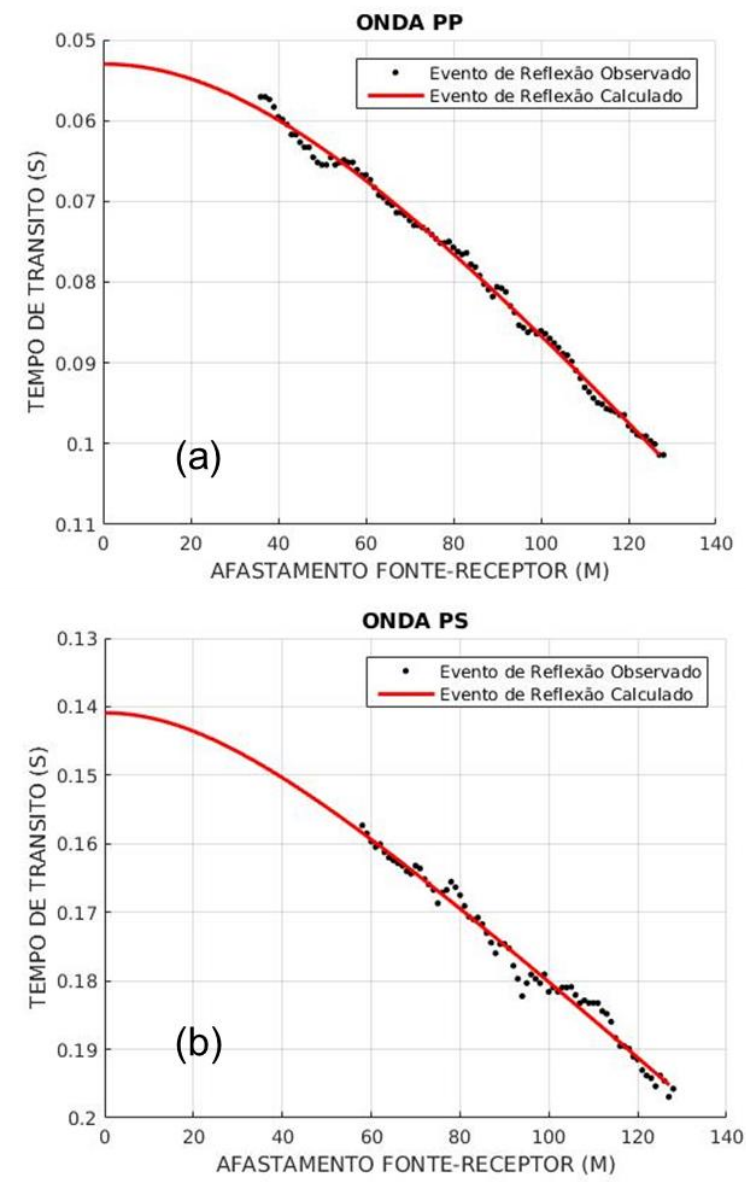

Figura 8 - Tempos de trânsito observados (pontos pretos), e os tempos de trânsito obtidos pela inversão (curva vermelha): (a) Onda PP; (b) Onda PSv. 
Determinação de coeficiente de Poisson do substrato rochoso a partir de análise dos dados sísmicos de onda P e onda PS 4 registradas apenas no plano vertical

\begin{tabular}{|c|c|c|l|}
\hline \multirow{2}{*}{ Tipo de Onda } & \multicolumn{3}{|c|}{ Parâmetros } \\
\cline { 2 - 4 } & $\mathrm{t}(0)$ & Vrms & $\mathrm{S}$ \\
\hline PP & $0.0531 \mathrm{~s}$ & $1420,57 \mathrm{~m} / \mathrm{s}$ & 1,23 \\
\hline PSv & $0.141 \mathrm{~s}$ & $709,84 \mathrm{~m} / \mathrm{s}$ & 5,67 \\
\hline
\end{tabular}

Sheriff, R. E., 2002. Encyclopedic Dictionary of Applied Geophysics. 4th ed. Tulsa: Society of Exploration Geophysicists.

Stockwell, J. W.; Coher, J. K., 1998. The New SU User's Manual. CWP Colorado School Mines, USA, version 2.2

Tabela 1 - Valores da velocidade, tempo normal e parâmetro $\mathrm{S}$, estimados pela inversão de tempos de trânsito da onda P e PS.

\section{Cálculo de razão de Vp/Vs e coeficiente de Poisson}

De acordo com os testes, com os dados numéricos apresentados em Bokhonok (2011), o parâmetro estimado que apresenta o menor erro relativo é o tempo normal $\left(\mathrm{t}_{0}\right)$. Por esse motivo, para o cálculo de $\mathrm{Vp} / \mathrm{Vs}$ foram usados o tempo normal das ondas PP e ondas PS, como na equação 2 .

$$
\frac{V_{P}}{V_{S}}=\frac{2 t_{P S}}{t_{P P}}-1
$$

O coeficiente de Poisson foi obtido utilizando a equação 1. O valor de razão $\mathrm{Vp} / \mathrm{Vs}$ obtido é de 4,31 e o valor do coeficiente de Poisson obtido é de 0,472.

\section{Conclusões}

A razão $\mathrm{Vp} / \mathrm{Vs}$ e o coeficiente de Poisson foram obtidos a partir dos tempos de trânsito da onda PP e PSV registrados com receptor vertical. Os valores indicam que o substrato rochoso no local de estudo é constituído predominantemente por sedimentos argilosos saturados.

\section{Agradecimentos}

ITA agradece à Universidade Católica de Santos pela bolsa de estudos de Iniciação Tecnológica (PROITI) ao IPECI e a todas as pessoas que me apoiaram na consecução deste trabalho.

OBC agradece ao Conselho Nacional de Desenvolvimento Científico e Tecnológico (CNPq) pela bolsa de Pós-doutorado (Processo: 159293/2015-4)

\section{Referências}

Bokhonok, O., 2010. Sísmica de reflexão rasa multicomponente: Aquisição e inversão de tempos de trânsito e amplitudes, IAG, Universidade de São Paulo.

Borges, W.R., 2002. Investigações geofísicas na borda da Bacia Sedimentar de São Paulo, utilizando-se GPR e Eletrorresistividade. Dissertação de Mestrado, IAG/USP. São Paulo, 153p.

Kearey, P.; Brooks, M.; Hill, I., 2002. An introduction to geophysical exploration. 3rd ed. Blackwell Science

Malovichko, A. A., 1978. A new representation of the traveltime curve of reflected waves in horizontally layered media. Applied Geophysics (in Russian), vol. 91: 47-53. 